
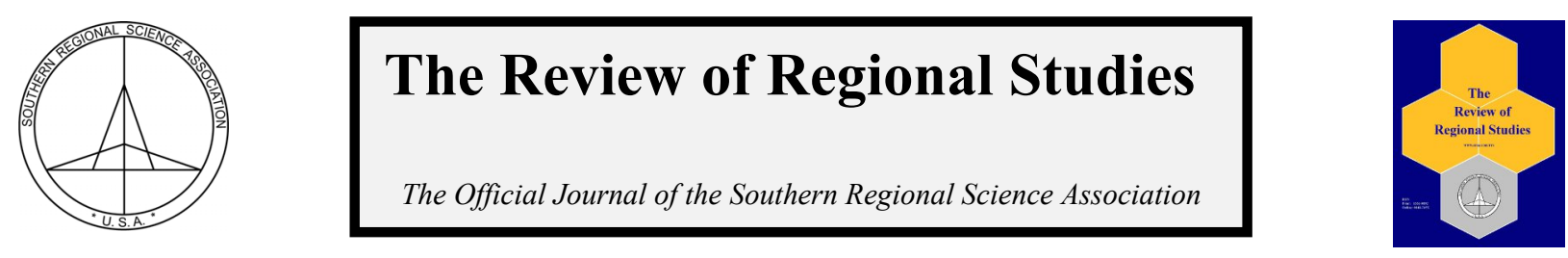

\title{
The Role of Regional Science in Shale Energy Development
}

\author{
Christa D. Court ${ }^{\mathrm{a}}$, Randall W. Jackson ${ }^{\mathrm{b}}$, and Nancy White ${ }^{\mathrm{c}}$ \\ ${ }^{a}$ MRIGlobal and Regional Research Institute, West Virginia University, USA \\ ${ }^{b}$ Regional Research Institute, West Virginia University, USA \\ ${ }^{c}$ Department of Economics, Bucknell University, USA
}

\begin{abstract}
The most recent boom in fossil fuel extraction is noteworthy through its extensive use of advanced technologies called hydraulic fracturing and horizontal drilling. The papers in this issue demonstrate the role that regional science can and should play in guiding policy, usefully complementing research from physical science and engineering disciplines that focuses on the important geological and environmental consequences of shale energy production. Furthermore, we underscore the need for expanding the traditional regional science focus in policy discussions pertaining to shale energy.
\end{abstract}

Keywords: regional science, shale energy, fracking, policy

JEL Codes: Q48, R12, R58

The popular press repeatedly reports that the United States (U.S.) is in a resource extraction boom, placing particular emphasis on benefits such as job creation and progress toward energy independence. Continuous fossil fuel extraction has in fact occurred in the U.S. for centuries; what makes this most recent boom noteworthy is the extensive use of advanced technologies called hydraulic fracturing and horizontal drilling. Although these technologies are not new, they have recently initiated the rapid production of so-called unconventional deposits of oil and gas in locations with little or no recent presence of the oil and/or gas industry, namely shale formations. Hydraulic fracturing - fracking - is geographically dispersed in as many as 37 states in the U.S., in part because the lower 48 states have abundant shale deposits containing vast natural gas resources. Known as "sweet spots" or "hot spots," the current sites with intensive drilling appear to have been chosen for the magnitude of profitable oil and gas deposits, which, in the absence of consistent policies regulating or prohibiting extraction, may be located in rural, suburban, or even urban areas. It should not be surprising that in 2011-12, there were 158 bills proposed in 26 states that address various aspects of shale oil and/or gas extraction (Pless, 2012). The subject of proposed legislation suggests present concerns of policymakers and citizen groups, such as: disclosure of the chemicals used in hydraulic fracturing, water protection, severance taxes, moratoria, and need for further study.

Hydraulic fracturing and horizontal drilling, along with oil and gas prices, are essential determinants in unconventional shale plays. Horizontal drilling allows for greater recovery of a resource from a single well; the lateral legs of the well can extend up to 5,000 feet from the

Court is a Staff Scientist at MRIGlobal and an Industry Liaison at the Regional Research Institute, West Virginia University, Morgantown, WV 26505. Jackson is the Director of the Regional Research Institute and Professor of Geology and Geography, West Virginia University, Morgantown, WV 26505. White is a Professor of Economics in the Department of Economics at Bucknell University, Lewisburg, PA 17837. Corresponding Author: N. White E-mail: nwhite@bucknell.edu

(C) Southern Regional Science Association 2013.

ISSN 1553-0892, 0048-749X (online)

www.srsa.org/rrs 
vertical well. Hydraulic fracturing involves perforating the stages of the lateral legs of the well casing with a string of small-scale explosives. Afterwards, a high-pressure injection of a mix of water, sand, and chemicals creates fractures in the earth through which oil and gas can flow for extraction. Each well requires millions of gallons of water. Each well produces oil and/or gas, often transported by truck to pipelines or rail. ${ }^{1}$ Under the Energy Policy Act of 2005, hydraulic fracturing was excluded from the Safe Drinking Water Act, except when diesel fuel is used in the fracking process.

The purpose of the set of articles in this issue is to demonstrate how regional science can be useful to public policymaking in locations undergoing shale energy development. As Lahr (2009) points out in "Regional Science, Regional Scientists, and State Policy," our theories and methods at the state level "may be the only geographically relevant work pertinent to [state policymakers'] current interests." In addition, each of the last three Southern Regional Science Association's Presidential Addresses (Connaughton, 2010; Jackson, 2011; and Woodward, 2012) has emphasized the opportunities and responsibilities of regional scientists to focus their research efforts on policy-relevant issues and to contribute to the decision making process. White's Fellow's Address, appearing in this issue, makes a clear call for high quality, independent, and policy relevant research on shale energy production and public policy. The papers in this issue demonstrate the role that regional science can and should play in guiding policy, usefully complementing research from physical science and engineering disciplines that focuses on the important geological and environmental consequences of shale energy production. Furthermore, we underscore the need for expanding the traditional regional science focus in policy discussions pertaining to shale energy.

Since the 1994 National Academy of Science publication of "Science Priorities for Human Dimensions of Global Change" (Committee on the Human Dimensions of Global Change, 1994) and the National Science Foundation and National Research Council's Grand Challenges initiatives of the late 1990s, a comprehensive approach to interdisciplinary research has been increasingly emphasized and in many cases required for large scale competitive research funding. The linkages among technology, economy, environment, the law, and health are intuitively obvious; however, comprehensive approaches to modeling and quantifying these linkages remain in their early stages, presenting both research challenges and funding opportunities. The interdisciplinary approach of regional science, with its explicit acknowledgement and treatment of spatial relationships, and its recognition of the important roles of local and regional processes to socioeconomic health and performance, makes regional scientists ideally suited to contribute to public policy debates in the technology-economyenvironmental nexus. Prudham (2002, p. 172), for example, notes that geography and regional analysis remain central to issues surrounding human-environment interactions and that "regional science can make important contributions in confronting the interrelationships of social and environmental transformations." Batabyal and Nijkamp (2004) also called for regional scientists to continue their interdisciplinary research endeavors of human-environment interactions and increase collaboration with other natural science and social science disciplines.

Estimates of the impact on local economies, especially job creation associated with shale energy extraction, are often reported in the popular press, many of which can be traced to industry-funded research. The academic community, including regional scientists, has begun to

${ }^{1}$ See Ground Water Protection Council and ALL Consulting (2009) on hydraulic fracturing and horizontal drilling.

(C) Southern Regional Science Association 2013. 
respond with independent research on the impact of shale energy production on jobs and incomes (Weinstein and Partridge, 2011; Kelsey, Shields, Ladlee, Ward 2011; Farren, Weinstein, and Partridge, 2012; Partridge and Weinstein, 2012). In addition to these economic impacts of shale energy extraction, there are many other possibilities, including impacts on air and water quality, housing values, transportation and regional trade networks, and even implications for international trade. Many disciplines are currently contributing to the body of knowledge associated with shale energy production. For example, legal scholars are discovering that current regulatory frameworks are not well suited to addressing the issues associated with hydraulic fracturing (Wiseman, 2009, 2010; Collins, 2010; Wiseman and Gradijan, 2011). Environmental scientists are studying the natural resource implications of increased shale gas development (Rahm and Riha, 2011). Still others are doing work on the broader environmental impacts of shale gas extraction (Currie and Stelle, 2010; Kargbo et al., 2010; Jiang et al., 2011).

The integration of geologists, ecologists, environmental scientists, industry experts, engineers, and legal professionals into the regional science scholarly community has the potential to improve our modeling approaches, increase the depth and applicability of the field, and allow us to contribute more effectively to public policy discussions. It is very clear to us at this time that shale energy production is a potent example demonstrating that spatial differences related to geography, geology, hydrology, and community require different policy approaches. If regional scientists do not collaborate with these other groups, we are likely to lose our place at the policy table.

Until these more complex linkages are developed, regional scientists have at their disposal a general suite of tools that can be effectively used across a broad spectrum of research areas including rural and regional development, labor markets, housing markets, local public finance, migration, Dutch Disease, and the natural resource curse. We briefly review a general selection of economic impact and econometric analysis tools and suggest their possible role in analyzing issues related to shale energy development.

Economic impact analysis can play a role in local and regional planning and in workforce development. Input-output models represent one of the many impact analysis tools that can be used for process based analyses through analyses of the macroeconomy. Input-output (I-O) process models (e.g., Lin and Polenske, 1998; Polenske and McMichael, 2002) provide ways of collecting, compiling, and ultimately embedding the cost structure or production function associated with a new or emerging industry Such models enable representation of new technologies, such as hydraulic fracturing, in regional and national accounts, as well as for other uses like impact analyses.

Using methods like structural decomposition analysis, I-O tables can be compared over time to examine and evaluate proximate causes of structural changes in the mode of shift-share analysis. In this way, I-O models can be used to examine the economic effects of the Marcellus Shale and Bakken Shale plays. Structural decomposition techniques in tandem with I-O models can also be used to compare similar economies with and without shale energy extraction in a cross-sectional manner.

The same technology-augmented I-O frameworks that support I-O process models and structural decomposition analyses can be extended to form the foundations for impact analyses based on social accounting matrices (SAM) and for policy and sensitivity analyses using computable general equilibrium (CGE) models that build upon and extend SAMs. Additionally, 
where life-cycle analyses (LCA) are undertaken by engineers or environmental scientists, methods have been developed for establishing explicit and formal linkages between LCA and IO analyses (Cooper, Jackson, and Leigh, 2008, 2012).

However, as Partridge and Weinstein point out, authors of "an impact study should tell how many jobs are supported, not created by the extractive industry." They point out that producing more natural gas can mean less coal production and argue that new natural gas jobs might come at a cost of coal jobs in some locations. There are also known drawbacks to some impact analyses that have not been carefully formulated or carried out including the omission of displacement effects, price effects, and the effects of new development crowding out other investment opportunities. Because regional scientists typically work across disciplines, they tend to take views of regional development processes that are broader and more holistic than those of others who work within a single discipline. That is, as a group, regional scientists should be more alert to multidimensional considerations.

Econometric methods represent another general set of tools that regional scientists can use to analyze shale energy development. Isard et al. (1998, p. 135) note that "[e]conometric methods are among the most important general-purpose tools available for the analysis of regional phenomena." These tools can also be applied to an extremely diverse range of problem domains from the micro to macro levels and have been used by regional scientists to model, understand, and forecast aspects of regional economies for decades.

Partridge and Weinstein (2012) mention three econometric methods in general that might be used by regional scientists to analyze shale energy development: matching, two stage least squares, and difference in difference methods. They offer these methods as possible solutions to difficulties such as the need to establish a counterfactual to shale development; the fact that shale development might be endogenous in the sense that places that accept drilling are different than other places; and, measuring the effect on the change in employment or income based on the change in the level of shale development, respectively.

These are only a few of the ways in which econometric methods could be applied to shale energy production. There are many additional relationships to model or understand, and these tools offer a range of solutions. Regional scientists are also skilled in applying a spatial dimension to econometric methods, i.e., spatial econometric methods (see LeSage and Pace, 2009). Spatial econometrics might be an ideal tool for analyzing aspects of economic development, especially given the spatial dimension of shale oil and gas deposits.

The regional science tools described above are a small sample of those available. Costbenefit analysis, contingent valuation and revealed preference methods, analysis of land use change, methods related to migration and local labor markets, and spatial interaction models are examples of some of the others likely to play important roles in the analysis of shale energy development. Some of these methods and topics are prominent in the papers in this issue. Each of the papers contains a useful literature review containing background information on the methods used and promotes future research on the topic. The papers are arranged as follows.

Nancy White's Fellows Address starts out the issue by laying out stories of two shale plays: the Bakken Shale in North Dakota and the Marcellus Shale in Pennsylvania. In the summer of 2012, North Dakota rose to second place, behind Texas, in U.S. domestic crude oil production. North Dakota is both an agricultural and energy-producing state, with coal, oil, wind, and natural gas resources. The popular press stories that White emphasizes illustrate the 
challenges of meeting labor and housing demands when the scale of a resource boom overwhelms the ability of a somewhat isolated location to satisfy those demands. Furthermore, these two shale plays show how people and places are linked. For small towns such as Williston, North Dakota, a center of much Bakken activity, the local economic development question is one of sustainability. As Kraybill and Kilkenny (2003) point out, the effects of a group (such as outmigration of long-time residents in response to changes in quality of life) on a single individual is much larger than in an urban area. The chief concern for policymakers in North Dakota is how simultaneously to meet the current needs of its citizens and the industry while planning for a sustainable future that includes economic diversity beyond energy and agriculture. Economic development outcomes are a result of careful planning and fiscal responsibility in the present.

Following White's piece, Steven Deller and Andrew Schreiber show the potential consequences to communities that provide materials used in hydraulic fracturing. They expand the classic Carlino-Mills model to analyze the relationship between non-oil and gas extraction, including silicon sand used in hydraulic fracturing, and economic growth in nonmetropolitan U.S. counties from the period 2000-2007. The approach employed by these authors determines whether shale-related, non-oil and gas production influences population, employment, and income growth. Their work suggests a relationship only between income growth and non-oil and gas extraction.

That is followed up by Stratford Douglas and Annie Walker's paper entitled "Sample Selection in Appalachian Research," which provides future researchers, especially those analyzing the impacts of the Marcellus Shale, with an approach to sample selection issues and the natural resource curse. The importance of sample selection in studies of the natural resource curse within a country is made clear when the authors state: "[I]f regions are thought of as experimental subjects receiving a random treatment of resource endowments, the experiment will more reliably detect the treatment effect if the subjects are otherwise homogenous." The sampleselection algorithm that the authors develop to identify the counties that belong to the Appalachian region is based on three criteria: topography, contiguity, and prevalence of slavery in the 1860 census. They then demonstrate the advantages, in terms of noise and bias, of their method of sample selection by using it to select samples for a set of county-level panel data regressions on per capita income growth and coal extraction.

Real estate valuation and shale energy extraction is the subject of the paper by Clifford Lipscomb, Yongsheng Wang, and Sarah Kilpatrick. The contribution of their article to the present issue is threefold. First, the authors discuss the legal relationship between property value and the property owner's shale gas rights. Lipscomb, Wang, and Kilpatrick then introduce the concepts of mortgageability and insurance, along with legal and regulatory changes to the discussion of real estate valuation and hydraulic fracturing, with a focus on Pennsylvania's Act 13. Future researchers might benefit from the authors' discussion of the possible link between scientific and public health information and the role of this information in real estate market transactions. The authors provide insights into why contingent valuation methods might be more efficacious than revealed-preference methods (e.g., hedonic models) for analysis of shale energy extraction and changes in real estate valuation.

Shale resource extraction is likely to drive energy production in the United States in the future. The collection of papers in this issue reinforce the value of a regional science approach to energy-based regional development, both reaffirming and expanding the potential contribution of regional scientists to public policy.

(C) Southern Regional Science Association 2013. 


\section{REFERENCES}

Batabyal, Amitrajeet A. and Peter Nijkamp. (2004) "The Environment in Regional Science: An Eclectic Review," Papers in Regional Science, 83, 291-316.

Collins, Emily A. (2010) "New Withdrawals, New Impairments as Pennsylvania Develops the Marcellus Shale," University of Pittsburgh Legal Studies Research Paper No. 2010-34. Available at: http://dx.doi.org/10.2139/ssrn.1699731.

Committee on the Human Dimensions of Global Change. (1994) Science Priorities for Human Dimensions of Global Change. National Academy Press: Washington, DC.

Connaughton, John E. (2010) "Local Economic Impact of the Great Recession of 2008/2009," The Review of Regional Studies, 40, 1-4.

Cooper, Joyce, Randall W. Jackson, and Nancey Green Leigh. (2008) "Modeling Regional Recycling and Remanufacturing Processes: From Micro to Macro," Regional Research Institute Working Paper \# 2008-6. Available at: http://www.rri.wvu.edu/pdffiles/jacksonwp2008-6.pdf.

Cooper Joyce, Randall W. Jackson and Nancey Green Leigh. (2012) "Computational Structure for Linking Life Cycle Assessment and Input-Output Modeling: A Case Study on Urban Recycling and Remanufacturing," in Frank Giarratani, Geoffrey J.D. Hewings and Phillip McCann, eds., Handbook of Economic Geography and Industry Studies. Edward Elgar: Cheltenham, U.K. Currie, Katrina M. and Elizabeth B. Stelle. (2010) "Pennsylvania's Natural Gas Boom: Economic and Environmental Impacts," Policy Brief from the Commonwealth Foundation, 22(5), 1-12. Available at http://www.commonwealthfoundation.org/doclib/20100607_marcellusshaledrilling.pdf.

Farren, Michael, Amanda L. Weinstein, and Mark D. Partridge. (2012) "Making Shale Development Work for Ohio," Swank Program in Rural-Urban Policy Summary and Report. Department of Agricultural, Environmental, and Development Economics, The Ohio State University, last accessed in January 2012 at http://aede.osu.edu/sites/drupal-aede.web/files/Making Shale Development Work for Ohio June 1.pdf.

Ground Water Protection Council and ALL Consulting. (2009) Modern Shale Gas Development in the United States: A Primer, a report prepared under contract DE-FG26-04NT15455 for the U.S. Department of Energy, Office of Fossil Energy and National Energy Technology Laboratory, last accessed in January 2012 at http://www.netl.doe.gov/technologies/oil-gas/publications/EPreports/Shale_Gas_Primer_2009.pdf.

Isard, Walter, Iwan J. Azis, Matthew P. Drennan, Ronald E. Miller, Sidney Saltzman, and Erik Thorbecke. (1998) Methods of Interregional and Regional Analysis. Ashgate Publishing Company: Brookfield, VT.

Jackson, Randall W. (2011) "2011 SRSA Presidential Address: Knowns, Unknowns, and Impacts, ” The Review of Regional Studies, 41, 5-11.

Jiang, Mohan, W. Michael Griffin, Chris Hendrickson, Paulina Jaramillo, Jeanne VanBriesen, and Aranya Venkatesh. (2011) "Life Cycle Greenhouse Gas Emissions of Marcellus Shale Gas,” Environmental Research Letters, 6(3), 034014 (9pp). 
Kargbo, David M., Ron G. Wilhelm, and David J. Campbell. (2010) "Natural Gas Plays in the Marcellus Shale: Challenges and Potential Opportunities," Environmental Science and Technology, 44, 5679-5684.

Kelsey, Timothy, Martin Shields, James Ladlee, and Melissa Ward (2011) "Economic Impacts of Marcellus Shale in Pennsylvania: Employment and Income in 2009," Marcellus Shale Education and Training Center report. Available at www.msetc.org.

Lahr, Michael L. (2009). "Regional Science, Regional Scientists, and State Policy," International Regional Science Review, 32, 495-507.

LeSage, James P. and R. Kelley Pace. (2009) Introduction to Spatial Econometrics. CRC Press: Boca Raton, FL.

Partridge, Mark D. and Amanda Weinstein. (2012) "Measuring the Economic Value of Shale Gas Energy Development," presented at the Bucknell University/Southern Regional Science Association Shale Workshop at Bucknell University, July 31.

Pless, Jacqueline (2012). "Hydraulic Fracturing: States Take Action," publication for the National Conference of State Legislatures. Available at http://www.ncsl.org/documents/energy/Pless121912.pdf.

Prudham, W. Scott. (2002). "Regional Science, Political Economy, and the Environment," Canadian Journal of Regional Science, 25, 171-206.

Rahm, Brian G. and Susan J. Riha. (2012) "Toward Strategic Management of Shale Gas Development: Regional, Collective Impacts on Water Resources," Environmental Science and Policy, 17, 12-23.

Riha, Susan J. and Brian G. Rahm. (2010) "Framework for Assessing Water Resource Impacts From Shale Gas Drilling," Clear Waters, 40, 16-19.

Weinstein, Amanda L. and Mark D. Partridge. (2011) "The Economic Value of Shale Natural Gas in Ohio," Swank Program in Rural-Urban Policy Summary and Report. Department of Agricultural, Environmental, and Development Economics, The Ohio State University, http://aede.osu.edu/sites/drupal-aede.web/files/Economic Value of Shale Dec 2011.pdf.

Wiseman, Hannah J. (2009) "Untested Waters: The Rise of Hydraulic Fracturing in Oil and Gas Production and the Need to Revisit Regulation," Fordham Law Review, 20, 115. Available at: http://ssrn.com/abstract $=1595092$.

. (2010) "Regulatory Adaptation in Fractured Appalachia," Villanova Environmental Law Journal, 21, 229.

Wiseman, Hannah J. and Francis Gradijan. (2011) "Regulation of Shale Gas Development, Including Hydraulic Fracturing," University of Tulsa Legal Studies Research Paper No. 2011-11. Available at: http://papers.ssrn.com/sol3/papers.cfm?abstract_id=1953547.

Woodward, Douglas. (2012) "Presidential Address: Industry Location, Economic Development Incentives, and Clusters," The Review of Regional Studies, 42, 5-23. 